\title{
Use of biologics in a patient with rheumatoid arthritis refractory to methotrexate
}

\author{
Jasvinder A. Singh MBBS MPH
}

A 29-year-old business executive with a 3-year history of rheumatoid arthritis presents because of worsening joint swelling and pain involving her hands, wrists and feet over the last 2 months and because of substantial limitations in her work and daily activities. Her symptoms had previously responded to combination treatment with sulfasalazine and hydroxychloroquine given orally and methotrexate injected subcutaneously, a regimen that she is still taking regularly. She now has 2-4 hours of morning stiffness in several joints, up from a baseline of 15 minutes. Examination shows 8 swollen and 10 tender joints, with extensive involvement of the metacarpophalangeal and proximal interphalangeal joints, wrists and metatarsophalangeal joints. There are 2 erosions seen on a hand radiograph and 1 erosion on a foot radiograph. The patient saw a rheumatologist, who recommended that she start taking a biologic. She feels confused by so many choices of biologics and their risks and benefits and wants to discuss these issues with her primary care physician.

\section{What are this patient's treatment options?}

Biologics are effective treatment options for rheumatoid arthritis that help to decrease joint pain and swelling, reduce destruction shown on radiographs and improve the patient's function and quality of life. ${ }^{1}$ Developed and produced in live cell systems, biologics are indicated when treatment with single or multiple traditional disease-modifying antirheumatic drugs (DMARDs), including methotrexate, is not effective. ${ }^{2}$

Biologics can be administered in different formats: as subcutaneous injections (etanercept, adalimumab, golimumab, certolizumab pegol, abatacept and, rarely, anakinra) that can be given at home; and as intravenous infusions (abatacept, rituximab, infliximab and tocilizumab), which are administered in a doctor's office or at an infusion centre. Biologics can be broadly categorized as those targeting tumour necrosis factor (etanercept, adalimumab, golimumab, certolizumab pegol and infliximab) or targeting other cytokines or cells (abatacept, anakinra, rituximab and tocilizumab). In addition to biologics, another new option is tofacitinib, an orally administered medication that is a selective inhibitor of Janus kinase enzymes.

Published head-to-head trials comparing these biologics were lacking until recently. A placebo-controlled randomized trial evaluated the efficacy and safety of abatacept and infliximab, but it was not powered to detect differences between the drugs. ${ }^{3}$ One recently published head-to-head noninferiority trial compared weekly subcutaneous injections of abatacept and biweekly subcutaneous injections of adalimumab in patients with active rheumatoid arthritis who had not responded well to methotrexate. ${ }^{4}$ The 2 medications had similar efficacy for improving patient symptoms, comparable inhibition of radiographic progression, and similar safety profiles with similar rates of serious adverse events and serious infections. ${ }^{4}$ Another head-to-head trial comparing tocilizumab and adalimumab is underway. Comparative studies of the safety of biologics are lacking. Indirect comparisons of biologics have been published, but these studies had limitations related to differences in patient populations, number and type of medications that failed, severity and activity of rheumatoid arthritis, and the heterogeneity of effect sizes. ${ }^{5,6}$

The 2012 treatment recommendations of the American College of Rheumatology offer detailed guidance for the use of biologics for rheumatoid arthritis $^{2}$ (Appendix 1, available at www.cmaj.ca /lookup/suppl/doi:10.1503/cmaj.121607/-/DC1). The choice of biologics is often driven by patient preferences regarding route of administration, frequency and perception of adverse effects, and outof-pocket costs.
Competing interests: There are no financial conflicts related directly to this paper. Jasvinder Singh has received research grants from Takeda

Pharmaceuticals and Savient Pharmaceuticals, and consultant fees from URL Pharma, Savient, Takeda, Ardea Biosciences, Regeneron Pharmaceuticals, Allergan and Novartis Pharmaceuticals.

This article has been peer reviewed.

Correspondence to: Jasvinder A. Singh, Jasvinder.md@gmail.com

CMAJ 2013. DOI:10.1503 /cmaj.121607 


\section{What adverse effects can occur with biologics?}

The safety profile differs by type of biologic. ${ }^{5}$ Injection- or infusion-related reactions are common but are usually mild; more severe systemic reactions requiring discontinuation of use are rare. The use of most biologics increases the risk of infection. Because this patient is young, this risk is low. The use of biologics also increases the risk of opportunistic infection, such as fungal or mycobacterial infection, which can present with nonspecific symptoms such as appetite loss, low-grade fever, cough, shortness of breath and skin lesions or other systemic symptoms. Rare adverse effects, such as progressive multifocal leukoencephalopathy, may occur, especially with rituximab.?

Biologics do not seem to be associated with an increased risk of cancer overall among patients with rheumatoid arthritis, ${ }^{8,9}$ although there may be a slight increase in the risk of skin cancers. ${ }^{10,11}$ Whether biologic use increases the risk of lymphoma beyond that associated with rheumatoid arthritis is controversial; ${ }^{5,11,12}$ major limitations of the current data are lack of long-term follow-up and the need for very large samples because of the rarity of this event.

Biologics are contraindicated in patients who have untreated chronic hepatitis B, those with treated chronic hepatitis B who are in the ChildPugh class B or C category, and patients who have New York Heart Association class III or IV heart failure and an ejection fraction of less than $50 \%{ }^{2}$

\section{Given the increased risk of infection, what vaccinations should be considered?}

The immunization status of patients should be reviewed to ensure that all vaccinations appropriate to their age, sex and occupation have been administered before biologics are started. Commonly recommended vaccinations include intramuscular pneumococcal and herpes zoster vaccines for people over 65 years of age, human papillomavirus vaccine for sexually active women, hepatitis B vaccine for health care workers and influenza vaccine for all patients. Patients already taking a biologic can be given these vaccines, except for the herpes zoster vaccine because it is an attenuated live vaccine.

\section{What about screening for tuberculosis?}

All patients prescribed biologics need to be screened for exposure to tuberculosis before starting treatment. A tuberculin skin test or interferon$\gamma$-release assay (IGRA) is the initial test, followed by a chest radiograph if indicated. ${ }^{2}$ If the skin test or IGRA result is negative or the patient has completed treatment for active or latent tuberculosis detected during screening, the biologic can be started (Appendix 2, available at www.cmaj.ca /lookup/suppl/doi:10.1503/cmaj.121607///DC1). ${ }^{2}$

In patients who have previously received a BCG vaccine, IGRA is preferred over skin testing because of the high frequency of falsepositive results with the latter in such instances. ${ }^{2}$ Patients with risk factors for tuberculosis (e.g., close contacts, foreign-born patients, frequent travellers to areas with a high prevalence of tuberculosis, health care workers, residents and employees in correctional facilities or long-term care facilities, homeless people and people in low-income groups) need to be monitored annually for tuberculosis infection or reactivation., ${ }^{2,13}$

\section{What precautions should this patient follow with biologics?}

Patients should be advised to stop taking the biologic if they get a fever, chills, rigor or other symptoms suggestive of infection and to contact their physician. An untreated infection can become serious in an immunosuppressed patient with rheumatoid arthritis who is taking a biologic. Because of the immunosuppression, there may be no febrile response to an infection. The physician should suspect infection and proceed with a careful evaluation followed by prompt and appropriate treatment. This patient is advised to follow up with her rheumatologist for routine monitoring for treatment response and adverse effects specific to the biologic being used.

\section{The case revisited}

After a detailed discussion with her primary care physician, the patient decides to start treatment with a biologic agent and to get her influenza vaccine. She is up to date with her other vaccines. She undergoes tuberculosis screening with a tuberculin skin test, and the result is negative. Because biologics in combination with methotrexate work better than methotrexate alone in patients whose rheumatoid arthritis no longer responds optimally to methotrexate, ${ }^{14,15}$ and because she responded well to methotrexate previously, her rheumatologist prescribes selfinjectable subcutaneous etanercept and continuation of the subcutaneous methotrexate. Three months later, her pain, swelling and other symptoms of rheumatoid arthritis are improved by $75 \%$, her quality of life has returned to close to baseline, and she is able to perform well at her job and in her social life.

\section{References}

1. Strand V, Singh JA. Newer biological agents in rheumatoid arthritis: impact on health-related quality of life and productivity. Drugs 2010;70:121-45.

2. Singh JA, Furst DE, Bharat A, et al. 2012 update of the 2008 American College of Rheumatology recommendations for the use of disease-modifying antirheumatic drugs and biologic 
agents in the treatment of rheumatoid arthritis. Arthritis Care Res (Hoboken) 2012;64:625-39.

3. Schiff M, Keiserman M, Codding C, et al. Efficacy and safety of abatacept or infliximab vs placebo in ATTEST: a phase III, multi-centre, randomised, double-blind, placebo-controlled study in patients with rheumatoid arthritis and an inadequate response to methotrexate. Ann Rheum Dis 2008;67:1096-103.

4. Weinblatt ME, Schiff M, Valente R, et al. Head-to-head comparison of subcutaneous abatacept versus adalimumab for rheumatoid arthritis: findings of a phase IIIb, multinational, prospective, randomized study. Arthritis Rheum 2013;65:28-38.

5. Singh JA, Wells GA, Christensen R, et al. Adverse effects of biologics: a network meta-analysis and Cochrane overview. Cochrane Database Syst Rev 2011;(2):CD008794.

6. Singh JA, Christensen R, Wells GA, et al. A network metaanalysis of randomized controlled trials of biologics for rheumatoid arthritis: a Cochrane overview. CMAJ 2009;181:787-96.

7. Carson KR, Evens AM, Richey EA, et al. Progressive multifocal leukoencephalopathy after rituximab therapy in HIV-negative patients: a report of 57 cases from the Research on Adverse Drug Events and Reports project. Blood 2009;113:4834-40.

8. Lopez-Olivo MA, Tayar JH, Martinez-Lopez JA, et al. Risk of malignancies in patients with rheumatoid arthritis treated with biologic therapy: a meta-analysis. JAMA 2012;308:898-908

9. Strangfeld A, Hierse F, Rau R, et al. Risk of incident or recurrent malignancies among patients with rheumatoid arthritis exposed to biologic therapy in the German biologics register RABBIT. Arthritis Res Ther 2010;12:R5.

10. Amari W, Zeringue AL, McDonald JR, et al. Risk of nonmelanoma skin cancer in a national cohort of veterans with rheumatoid arthritis. Rheumatology (Oxford) 2011;50:1431-9.

11. Wolfe F, Michaud K. Biologic treatment of rheumatoid arthritis and the risk of malignancy: analyses from a large US observational study. Arthritis Rheum 2007;56:2886-95.

12. Dommasch E, Gelfand JM. Is there truly a risk of lymphoma from biologic therapies? Dermatol Ther 2009;22:418-30.

13. CDC. Targeted tuberculin testing and treatment of latent tuberculosis infection. MMWR Recomm Rep 2000;49(RR-6):1-51.

14. Kuriya B, Arkema EV, Bykerk VP, et al. Efficacy of initial methotrexate monotherapy versus combination therapy with a biological agent in early rheumatoid arthritis: a meta-analysis of clinical and radiographic remission. Ann Rheum Dis 2010;69:1298-304 .
15. Ma MH, Kingsley GH, Scott DL. A systematic comparison of combination DMARD therapy and tumour necrosis inhibitor therapy with methotrexate in patients with early rheumatoid arthritis. Rheumatology (Oxford) 2010;49:91-8.

Affiliations: From the Medicine Service and the Center for Surgical and Medical Acute care Research and Transitions (C-SMART), Birmingham VA Medical Center, Birmingham, Ala; the Department of Medicine at the School of Medicine, University of Alabama, Birmingham, Ala.; and the Department of Orthopedic Surgery, Mayo Clinic College of Medicine, Rochester, Minn.

Acknowledgement: The author thanks Dr. James O'Dell for providing valuable feedback and edits on this paper.

Funding: This material was not funded by any grant. Jasvinder Singh is supported by the resources and use of facilities at the Birmingham VA Medical Center.

Decisions is a series that focuses on practical evidence-based approaches to common presentations in primary care. The articles address key decisions that a clinician may encounter during initial assessment. The information presented can usually be covered in a typical primary care appointment. Articles should be no longer than 650 words, may include one box, figure or table and should begin with a very brief description (75 words or less) of the clinical situation. The decisions addressed should be presented in the form of questions. A box providing helpful resources for the patient or physician is encouraged.

\title{
How you can get involved in the CMA!
}

The CMA is committed to providing leadership for physicians and promoting the highest standard of health and health care for Canadians. To strengthen the association and be truly representative of all Canadian physicians the CMA needs to hear from members interested in serving in elected positions and on appointed committees and advisory groups. The CMA structure comprises both governing bodies and advisory bodies either elected by General Council or appointed by the CMA Board of Directors. The Board of Directors - elected by General Council — has provincial/territorial, resident and student representation, is responsible for the overall operation of the CMA and reports to General Council on issues of governance.

CMA committees advise the Board of Directors and make recommendations on specific issues of concern to physicians and the public. Five core committees mainly consist of regional, resident and student representation while other statutory and special committees and task forces consist of individuals with interest and expertise in subject-specific fields. Positions on one or more of these committees may become available in the coming year.

For further information on how you can get involved please go to http://www.cma.ca/membercentre/how-you-can-get-involved, or contact

\author{
Cherise Araujo \\ Corporate and Governance Services \\ Canadian Medical Association \\ 1867 Alta Vista Drive, Ottawa ON K1G 5 W8 \\ Fax 613 526-7570, Tel 800 663-7336 x1949 \\ cherise.araujo@cma.ca
}

By getting involved, you will have an opportunity to make a difference.

We hope to hear from you! 